\title{
Recommendations for the management of patients that require eye care during the SARS-CoV-2 pandemic
}

\section{Recomendaciones para el manejo de pacientes que requieren atención oftalmológica durante la pandemia de SARS-CoV-2}

\author{
Juan P. Olivares-de Emparan", Manuel Garza-Leon², Gerardo García-Aguirre³, Tonath Azcárate-Coral', \\ Jason A. Penniecook ${ }^{5}$, Van Charles Lansingh ${ }^{6,7}$ and Jesús Jiménez-Román ${ }^{8 *}$
}

INFORMATIVE NOTE: This manuscript has gone through an exceptional peer review process in order to speed up the publication process as it is urgent news of special interest among the ophthalmology community.

${ }^{1}$ Anterior Segment Department, Asociación para Evitar la Ceguera en México, Mexico City, Mexico; ${ }^{2}$ Department of Clinical Sciences of the Division of Health Sciences, Universidad de Monterrey, San Pedro Garza García, NL, Mexico; ${ }^{3}$ School of Medicine, Tecnológico de Monterrey, Monterrey, NL, Mexico; ${ }^{4}$ Academic Committee, College of Ophthalmologists of the State of Yucatan, Yucatan, Mexico; ${ }^{5}$ nstituto de la Visión, Universidad de Montemorelos, Montemorelos, NL, Mexico; ${ }^{6}$ Instituto Mexicano de Oftalmología, Querétaro, Qro., Mexico; ${ }^{7} \mathrm{Help}$ Me See, New York, USA; ${ }^{8}$ Glaucoma Service, Asociación para Evitar la Ceguera en México, Mexico City, Mexico

\section{Executive summary}

The current SARS-CoV-2 coronavirus pandemic has been strongly linked to ophthalmology since it began. On January 10, 2020, the New York Times announced that Dr. Li had contracted the disease after attending a patient with acute glaucoma. On March 11, 2020, the World Health Organization declared a pandemic ${ }^{1}$. The high transmission rate of the virus puts Mexico in a scenario where, according to the Ministry of Health, it is estimated that the virus could infect $70 \%$ of the country's population and that, only in its acute stage, the epidemic could last at least 12 weeks in our country.

Transmission method:

- It is due to aerosols when in contact with a person who carries the virus or who suffers from the disease COVID-192-4.

- The entry of the virus through the mucosa after touching surfaces or objects where the virus is present (fomites) $)^{2-4}$.
- The virus has an incubation period of 2 to 14 days, with an average of 5 to 7 days. Ninety-seven percent of patients develop symptoms in 11.5 days, hence the importance of isolation for 14 days 1 . Clinical presentation:

- Fever above $38{ }^{\circ} \mathrm{C}$ in $90 \%$ of cases.

- Dry cough in up to $70 \%$ of cases.

- General malaise and headache.

- In 2 to $3 \%$ of cases, there may be gastrointestinal disturbances.

- To date, there is no effective treatment or vaccine against the disease ${ }^{2}$.

Relationship of COVID-19 with ophthalmology:

- Presence of the SARS-CoV-2 virus in the tears of patients with COVID-191,5.

- Nonspecific conjunctivitis has been described ${ }^{5,6}$.

- The ophthalmologist's working distance increases the risk of transmission.

Recommendations for ophthalmic management ${ }^{7-11}$ :
Correspondence:

*Jesús Jimenez-Román

E-mail: jimenez_roman@yahoo.com
Date of reception: $23-03-2020$

Date of acceptance: 24-03-2020

DOI:10.24875/RMOE.M20000122
Available online: 04-05-2020 Rev Mex Oftalmol (Eng). 2020;94(3):90-98 www.rmo.com.mx 2604-1731/@ 2020 Sociedad Mexicana de Oftalmología. Published by Permanyer. This is an open access article under the CC BY-NC-ND license (http://creativecommons.org/licenses/by-nc-nd/4.0/). 
- Categorize (triage) patients prior to admission to the waiting room.

- Hand washing of doctor and patient before starting the interviewing and exploration.

- Keep a two meter distance between doctor and patient during the interview.

- Use of a face shield on the slit lamp.

- Use of a surgical mask both by the doctor and the patient.

- Both the doctor and patient must wash hands or use an antibacterial gel at the end of the consultation.

- In the waiting room, avoid crowds, establish a distance of at least 1.5 meters between patients when seated.

- Space the appointments, in order to comply with the aseptic cleaning measures before and after each examination.

- Use only one cubicle for examination.

- In the case of suspected cases, the use of a 3-layer surgical mask by the patient and an N95 mask by the doctor, latex gloves for examination, a surgical gown and cap, and office disinfection are recommended.

- In confirmed cases, whether with mild or severe symptoms, the relevance of ophthalmic care should be assessed. If the patient does not have an urgent or serious condition, he/she could be evaluated later.

- Some international ophthalmology societies suggested attending only patients with ocular emergencies. Permanence and viability of the virus:

- The viability of the virus is of 4 hours on copper surfaces, 8 on cardboard and up to 72 on plastic and stainless steel ${ }^{4}$.

Cleaning and disinfection measures:

- Continuous handwashing and the use of protection elements are the basis to mitigate the spread of the virus.

- Cleaning floors, walls, surfaces in the office or clinic; chlorine diluted in water can be used.

Cleaning and disinfection in ophthalmology ${ }^{12-14}$ :

- Surgical soap and water for the staff's hand washing.

- Alcohol gel 70\% for disinfection of the staff's hands.

$-0.21 \%$ sodium hypochlorite solution for tonometer cleaning.

$-20 \mathrm{~mL}$ of NK-CIDE solution in $1 \mathrm{~L}$ of water to soak the surgical instruments.

- Quaternary ammonium solution for work surfaces (soak and let dry for 4 minutes).

The recommendations contained in this document must be adapted according to the particular circumstances of each team of healthcare professionals. These recommendations will vary as more evidence is generated regarding the impact of the disease on patients' eye care. For this reason, this document will be updated continuously as new recommendations emerge with enough scientific support to modify our eye care behavior.

\section{Introduction}

The current SARS-CoV-2 coronavirus pandemic is linked to ophthalmology since it began. On December 30, 2019, Dr. Li Wenliang, a 34-year-old ophthalmologist, observed 7 cases with an outbreak of interstitial pneumonia similar to the severe acute respiratory syndrome (SARS) at Wuhan Central Hospital. The specialist warned his colleagues through the WeChat social network about the likely outbreak. On January 10, 2020, the New York Times announced that Dr. Li had contracted the disease after attending a patient with acute angle-closure glaucoma, who got the disease from her daughter. Finally, the young ophthalmologist died on February $7,2020^{2,15}$.

On January 30, 2020, a month after Dr. Li's warning, the World Health Organization (WHO) declared the outbreak a public health emergency of international concern, and on March 11 it was declared a pandemic ${ }^{1}$. As of March 22, there were 294,110 cases reported in 187 countries or territories ${ }^{16}$. To consult updated data on the number of cases globally and regionally, we suggest to access the following links:

- WHO situational map (https://covid19.who.int)

- PAHO situational map (https://bit.ly/35lc5qE)

The high transmission rate of the virus puts Mexico in a scenario where, according to the Ministry of Health, it is estimated that the virus could infect $70 \%$ of the country's population and that, only in its acute stage, the epidemic could last at least 12 weeks in our country.

The complete eradication of transmission does not seem probable in the foreseeable future and, due to the current emergency situation, the Mexican Society of Ophthalmology and the Mexican Center for Preventive Visual Health invite the ophthalmic community of Mexico to carry out all the necessary actions to face, in an efficient way, the current health crisis in our country, reducing the risks for our patients, family members, work collaborators and for ourselves; while we continue to ensure the visual health of our population. 


\section{Relevant information and epidemiology of the disease}

The SARS-CoV-2 is an enveloped RNA virus with a single-strand. Coronaviruses have a zoonotic transmission, and the recently discovered species had not previously caused disease in humans ${ }^{2}$.

The mode of transmission is due to aerosols when in contact with a person carrying the virus or suffering from the disease, COVID-19; as well as the entry of the virus through the mucosa after touching surfaces or objects where the virus is present (fomites) $)^{2-4}$.

The virus has an incubation period of 2 to 14 days, with an average of 5 to 7 days $^{2}$. Ninety-seven percent of patients develop symptoms in 11.5 days, hence the importance of isolation for 14 days ${ }^{1}$. The basic reproduction number $(R 0)$ has been estimated at 2.2-3.02, which means that a person will infect 2.2 to 3 people during the course of their illness. To achieve control of the infection, the $R 0$ must decrease by 1 , so isolation and detection are of utmost importance.

Three epidemiological phases have been described depending on the origin of the cases and the number of these; some of the recommendations compiled in this document refer to these phases (Table 1):

About 4 out of 5 people with the disease require only isolation and supportive measures at home. The remaining $20 \%$ require hospitalization due to bilateral interstitial pneumonia, with up to $5 \%$ of patients requiring mechanical ventilation.

Risk factors for severe cases are age over 60 years and comorbidities, mainly immunodeficiencies, diabetes and hypertension.

The clinical presentation includes fever above $38^{\circ} \mathrm{C}$ in more than $90 \%$ of cases, dry cough in up to $70 \%$ of cases, in addition to general malaise and headache. There are atypical pictures with sputum in $28 \%$ of cases, and in 2 to $3 \%$ there may be gastrointestinal disorders such as vomiting or diarrhea ${ }^{2}$. International otorhinolaryngology societies ${ }^{17,18}$ have reported anosmia, hyposmia and dysgeusia as part of the clinical presentation, either isolated or associated with other typical symptoms, or even as the initial symptoms. The Spanish Society of Ophthalmology includes them in its recommendations as part of the symptoms to be questioned ${ }^{11}$.

To date, there is no effective treatment or vaccine against the disease ${ }^{2}$. Current treatment is based on general measures for symptom management at home and ventilatory support for cases requiring
Table 1. Epidemiological phases

\begin{tabular}{|l|l|}
\hline $\begin{array}{l}\text { Phase } \\
\begin{array}{l}\text { 1. Imported } \\
\text { cases }\end{array}\end{array}$ & $\begin{array}{l}\text { Detected cases originated outside the } \\
\text { country }\end{array}$ \\
\hline $\begin{array}{l}\text { 2. Community } \\
\text { transmission }\end{array}$ & $\begin{array}{l}\text { Transmission between people within the } \\
\text { country }\end{array}$ \\
\hline $\begin{array}{l}\text { 3. Epidemiological } \\
\text { stage }\end{array}$ & $\begin{array}{l}\text { Affecting thousands of people in different } \\
\text { geographical regions of the country }\end{array}$ \\
\hline
\end{tabular}

hospitalization. The first clinical trial for the development of a vaccine started on March 16, 2020.

The mortality rate has shown an increase since the pandemic started. As of March 22, 2020 it was $4.2 \%{ }^{19}$ and according to the trend, it could continue to increase as the natural history of the disease progresses. The mortality estimation with statistical models ranges from 5.3 to $8.4 \%$.

\section{Epidemiological data in Mexico}

The first confirmed case in our country was on February 28. According to official sources, as of March 22, there were 316 confirmed cases and 793 suspects. Confirmed cases have been detected in 31 states $^{19}$.

Asymptomatic carriers have been detected in the country and it is suspected that local transmission is already a fact despite not having been corroborated by the country's healthcare authorities. The first death occurred on March $18^{19}$. To consult updated data in Mexico, access:

Secretaría de Salud - Coronavirus/COVID-19. Comunicado técnico diario (https://bit.ly/2xqnIWu).

\section{Importance in ophthalmology}

From an ophthalmologic point of view, the presence of the SARS-CoV-2 virus has been described in the tears of patients with COVID-19,20,21. A nonspecific conjunctivitis has also been described in 0.8 to $1 \%$ of cases, considered one of the forms of presentation of the disease ${ }^{1,22}$.

There are numerous reports about the risk of transmission to healthcare personnel, including from asymptomatic patients ${ }^{1,3,22}$. To date, the specific risk of contracting the disease for ophthalmologists has not been determined; however, the working distance during slit-lamp examination and during ophthalmic procedures could increase the risk ${ }^{1,6}$. 
Intraocular infection with some strains of murine coronaviruses has been demonstrated in mice, which caused inflammation and degeneration of the retina (experimental coronavirus retinopathy) ${ }^{21}$.

The current epidemic may help us better understand the ability of SARS-CoV-2 to damage eye tissues; in the meantime, we must be alert to the evidence that emerges.

\section{Prevention and protection measures in the office and the hospital}

It has been shown that the distance that the expelled particles travel when speaking, sneezing or coughing will depend on the event, in addition to the environmental conditions. In a controlled study, Xie, et al. determined that expelled particles can travel 1 meter only when speaking and breathing, 2 meters in the case of coughing and 6 meters when sneezing ${ }^{23,24}$.

The permanence and viability of the virus on different surfaces was reported in the New England Journal of Medicine. In this study, the reported viability of the virus was of 4 hours on copper surfaces, 8 on cardboard and up to 72 on plastic and stainless steel ${ }^{4}$.

Therefore, cleaning and disinfection measures, together with hand washing and the use of protection elements, are the basis for mitigating the spread of the virus.

It is important to separate the doctor's work area and the examination area (do not mix supplies between areas).

\section{Cleaning and disinfection}

For cleaning floors, walls, surfaces in the office or clinic, the use of chlorine diluted in water is recommended. The U.S. Centers for Disease Control (CDC) recommend ${ }^{25}$.

- 4 small tablespoons $(20 \mathrm{~mL})$ in $1 \mathrm{~L}$ of water or,

- 5 large tablespoons $(75 \mathrm{~mL})$ in 1 gallon $(3.8 \mathrm{~L})$.

For cleaning and disinfection in ophthalmology, the following solutions can be used ${ }^{12-14}$ :

- Surgical soap and water for the staff's handwashing.

- Alcohol gel 70\% for disinfection of the staff's hands.

$-0.21 \%$ sodium hypochlorite solution for tonometer cleaning.

- $20 \mathrm{~mL}$ of NK-CIDE solution in $1 \mathrm{~L}$ of water to soak the surgical instruments that will be used in the office.

- Quaternary ammonium solution for work surfaces (soak and let dry for 4 minutes).

\section{Hand washing and use of protection elements}

Due to the risk of transmission, and since the examination distance of our specialty is less than 1 meter, it is recommended:

FOR PATIENTS WITH NO HISTORY OF EXPOSURE (BASIC PROTECTION LEVEL) $)^{9,11}$

- During the interview:

- Hand washing before starting the interview and using the keyboard.

- Two meter distance between doctor and patient during the interview.

- During the examination:

- Use of a face shield in the slit-lamp and surgical mask for both the doctor and the patient; use of nitrile gloves to touch the patient, if necessary.

- If supplies are brought to the slit-lamp table, they should remain there until disinfected.

- Disinfect the office between patients.

- Doctors must wash their hands at the end of the consultation.

\section{FOR SUSPICIOUS PATIENTS (INTERMEDIATE PROTECTION LEVEL)}

The Spanish Society of Ophthalmology recommends treating only patients with ocular emergencies in the absence of symptoms of the disease ${ }^{11}$. If necessary, the protective measures are ${ }^{9,26}$ :

- During the interview:

- Hand washing before starting the interview and using the keyboard.

- Two meter distance between doctor and patient during the interview.

- Use of a 3-layer surgical mask by the patient and an N95 mask by the doctor.

- During the examination:

- Use of a face shield on the slit-lamp and industrial face shield if the exam is outside the slit-lamp.

- Use of a disposable surgical cap.

- Use of latex gloves (nitrile gloves in case of allergy of the doctor or the patient).

- Use of a surgical mask by the patient and an N95 mask by the doctor, as well as protective glasses that seal on the doctor's skin.

- Use of a disposable surgical gown by the doctor.

- If supplies are brought to the slit-lamp table, they should remain there until disinfected. 
- Disinfect the office between patients.

- Doctors must wash their hands at the end of the consultation.

\section{FOR PATIENTS WITH A CONFIRMED POSITIVE TEST FOR SARS-CoV-2}

They should be referred to a suitable hospital for management. Ophthalmic care is not recommended until an emergency physician or trained personnel to manage these cases has evaluated the patient from a systemic point of view ${ }^{11}$.

For ophthalmologists attending these patients in referral hospitals, the recommendations are ${ }^{11,26}$ :

- Attend in a designated office.

- Have all the recommended or available protection depending on the center.

- Take special care when in contact with the conjunctiva of patients.

- Discard all supplies and multi-dose drop bottles that were used during the consultation.

For more information regarding the protection of healthcare personnel, it is recommended to review the Manual for the Prevention and Treatment of COVID-19 of the First Affiliated Hospital, Zhejiang University School of Medicine, which will be available in Spanish in the coming days.

Handbook of COVID-19 Prevention and Treatment.

\section{Specific recommendations for the care of ophthalmic patients}

The initial recommendation is to perform an epidemiological categorization (triage) of patients who seek ophthalmic care, by requesting the following information ${ }^{10,11}$ :

- Presence of symptoms: fever, cough, malaise, headache, diarrhea and gastrointestinal disturbances, anosmia and dysgeusia.

- History of travel outside of Mexico in the last 14 days (phase 1 of the epidemic).

- History of cohabitation or contact with a suspected or confirmed case of COVID-19 (phases 2 and 3 of the epidemic).

In addition to the epidemiological categorization (triage), it is necessary to investigate the cause of requesting ophthalmic care. Some international ophthalmology societies recommend attending only urgent cases $7,8,11,27$. It is proposed to consider this recommendation to limit potentially contagious contacts. The final decision will

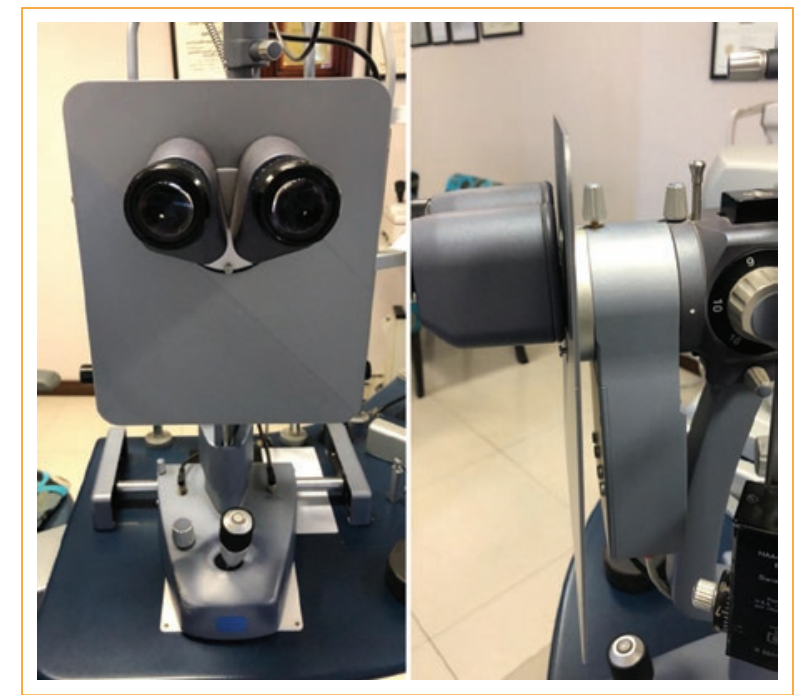

Figure 1. Placement and use of a face shield on the slit lamp.

Courtesy of Dr. Manuel Garza León.

depend on common sense and clinical evaluation, as well as the epidemiological phase at the moment.

Once we have decided that it is necessary to attend a patient, we must keep in mind that our main objective is to avoid exposing the patient and healthcare personnel to an infected patient. For this, we must follow the basic guidelines of public health, which include avoiding crowds in our facilities, so we must:

- Request that they come with only one companion.

- If possible, space the consultation in such a way that there are not two patients in the waiting room at the same time.

- Maintain the quarantine of patients with symptoms of the disease or confirmed diagnosis, so before taking the patient into the office, it is suggested to measure the temperature and, if it is equal to or greater than $38^{\circ} \mathrm{C}$, the patient must be referred to a suitable hospital.

Among the general care that we must use is the placement of a protective shield on the slit lamp (Fig. 1), the use of surgical or N-95 masks according to the risk of each patient (section 4) and cleaning hands with water and soap or $70 \%$ alcohol between patients, in addition to cleaning the surfaces that were in contact with the patient with a 10 or $20 \%$ sodium hypochlorite solution ${ }^{9,14}$.

The examination of patients with a suspected or confirmed diagnosis of COVID-19 should be done in hospitals with the necessary resources. In addition to the precautions already mentioned, the use of gloves, 
Table 2. Situations that we will face as ophthalmologists in our daily practice

\begin{tabular}{|c|c|}
\hline Situation & Recommendations \\
\hline $\begin{array}{l}\text { Follow-up of patients who do not have ocular } \\
\text { emergencies, without respiratory symptoms }\end{array}$ & $\begin{array}{l}\text { - Telephone or digital consultation* (whatsapp, skype) } \\
\text { - Suggest waiting for the health crisis to pass to seek care } \\
\text { - Advise to contact if the visual status changes }\end{array}$ \\
\hline $\begin{array}{l}\text { Follow-up of patients with diseases that require } \\
\text { follow-up in the office due to risk of visual loss } \\
\text { or ocular emergencies; in a healthy patient, } \\
\text { without clinical suspicion (fever, cough, } \\
\text { respiratory symptoms) or risk factors for } \\
\text { COVID-19 }\end{array}$ & $\begin{array}{l}\text { - Routine cleaning and disinfection precautions } \\
\text { - Use of a face shield on the slit lamp } \\
\text { - Use of a surgical mask by the doctor and the patient, as well as gloves } \\
\text { - To the extent possible, reduce follow-up visits and consider continuous care via } \\
\text { telephone or digital applications }\end{array}$ \\
\hline $\begin{array}{l}\text { Follow-up of patients (diseases that require } \\
\text { follow-up in the office due to risk of visual loss) } \\
\text { or ocular emergencies with respiratory } \\
\text { symptoms, but without fever or risk factors for } \\
\text { COVID-19 }\end{array}$ & $\begin{array}{l}\text { - Attention in the office } \\
\text { - Immediate use of a surgical mask by the patient when arriving at the office } \\
\text { - Use of a face shield on the slit lamp } \\
\text { - Use of protection by doctors, nurses and optometrists (gloves, protective } \\
\text { glasses, N-95 surgical masks) } \\
\text { - Disinfection of the entire office after examination }\end{array}$ \\
\hline $\begin{array}{l}\text { Patients with respiratory symptoms and fever, } \\
\text { with or without risk factors for COVID-19 }\end{array}$ & $\begin{array}{l}\text { - They must be referred to a hospital where they can be treated as a suspected } \\
\text { case of COVID-19 } \\
\text { - It is recommended to provide eye care in these institutions }\end{array}$ \\
\hline Patients with confirmed COVID-19 & $\begin{array}{l}\text { - Eye care will depend on the severity of the condition and the risk of } \\
\text { transmission to others } \\
\text { - Care is suggested only in centers designated for the management of patients } \\
\text { with the disease } \\
\text { - It is absolutely necessary to follow the security protocol (see section 4). Full } \\
\text { facial protection of healthcare personnel is of utmost importance }\end{array}$ \\
\hline
\end{tabular}

*Legal recommendations regarding the responsibility to provide care via telephone or applications due to the health crisis are still pending. †The risk factors and the epidemiological definition of the disease are continuously updated; we suggest to check updates in the following link: Secretaría de Salud - Aviso Epidemiológico COVID-19

protective glasses and suitable clothing should be added. This equipment should be disposed of in a hazardous waste disposal bag at the end of the examination (section 4).

One of the routine procedures in ocular examination is intraocular pressure (IOP) measurement; however, it is important to remember that studies of other coronaviruses suggest that the infection could be transmitted through the tears ${ }^{21}$, so we must decide if IOP measurement is necessary. If IOP measurement is essential, it is suggested to use contact methods and not air tonometers, since the application of an intense air force can cause aerosolization of the teardrops to the environment. Ideally, the contact surface should be disposable, so using a Tonopen or iCare might be the best option; however, due to accessibility, the Goldmann tonometer (the most widely used method) with disposable tips would be ideal. If disposable tips are not available, disinfection with a $10 \%$ sodium hypochlorite solution or, $70 \%$ alcohol as a second option must be performed $^{12}$.

Table 2 shows in a practical way the most common situations that we will face as ophthalmologists in our daily practice. Recommendations were generated with current knowledge. These could change quickly, and it is suggested to stay informed about the latest updates.

\section{Special situations}

\section{Patients under Immunomodulatory treatment}

As part of the treatment of various inflammatory diseases, some ophthalmologic patients may be using immunomodulatory agents, both biological (adalimumab, infliximab, rituximab, among others) and classic (methotrexate, azathioprine, cyclosporine, etc.). Due to the fact that up to now there is no scientific information that suggests a higher risk of COVID-19 or a worse evolution compared to patients that are not taking immunomodulators, in addition to the risk of visual loss if the drug is discontinued, the European League Against Rheumatism (EULAR) has suggested to continue treatment at the dose and frequency indicated by the healthcare professional28,29.

In the event of persistent fever or cough, the patient should follow the national advice for seeking medical 
care by calling the helplines. If the patient is positive for COVID-19, the advantages and disadvantages of discontinuing therapy should be discussed with the treating physician. In the meantime, if not already done, it would be prudent to complete vaccination in accordance with EULAR recommendations and national guidelines; currently, the priority is vaccination against influenza, whooping cough, and pneumococcus ${ }^{28}$.

It is interesting to know that since part of the tissue damage associated with COVID-19 is secondary to the immune response due to the presence of SARS-CoV-2 in the body, a randomized, double-masked study was recently initiated to evaluate the effect of tocilizumab (a humanized monoclonal antibody directed against the IL-6 receptor, approved for the treatment of rheumatoid arthritis) as adjunctive therapy for patients with severe pneumonia due to COVID-1930.

\section{Patients On the Waiting LIST FOR CORneal TRANSPLANTATION}

To date, the risk of corneal contamination from a patient who died from COVID-19 is unknown, in addition to not being a current part of the guidelines for serum screening studies of donor patients. However, the Eye Bank Association of America has imposed triage requirements to minimize the risk of procuring corneas from patients with COVID-1931. In Mexico, the National Transplant Center (CENATRA) recommends excluding organ donation in the following cases: suspected or confirmed cases of COVID-19 for a period of at least 21 days from resolution of symptoms or patients WITHOUT compatible clinical data, but with positive results in the screening tests ${ }^{32}$.

On March 17, the CENATRA issued recommendations to the national donation and transplant subsystem about the infection associated with SARS-CoV-2 (COVID-19), the most important being the TEMPORARY SUSPENSION of all organ and tissue donation and transplantation programs nationwide until further notice, with the exception of corneal tissue transplants already scheduled for the week of March 17-22, 2020, where the tissue is already available at the bank or in the facility. If it is essential to perform a transplant during the temporary suspension, the CENATRA must be notified through the corresponding channel. In addition, the inclusion of screening tests for COVID-19 is recommended as part of the pre-transplant tests in cases of national emergency, priority allocation, and corneal transplants scheduled for the week of March 17-22, $2020^{32}$.

\section{Contact lens adaptation and USE}

So far there is no evidence to recommend discontinuing the use of contact lenses in healthy patients. There is also no evidence that the use of contact lenses favors the spread of SARS-CoV-2 ${ }^{11}$.

Since there are reported cases of conjunctival infection, it is of utmost importance that contact lens wearers perform hand hygiene before and after contact lens insertion and removal. In addition, during the health crisis, the use of daily replacement contact lenses may be favored.

The Spanish Society of Contactology recommends that, during the health crisis, contact lenses that are not daily replaced, regardless of the material, should be disinfected with $3 \%$ hydrogen peroxide, replacing the use of multipurpose solutions ${ }^{11}$. We suggest considerin this recommendation for our patients; at the same time, do not disseminate the information to the general population, since disinfection with hydrogen peroxide requires prior training, due to the risk of damage to the ocular surface in case of improper handling.

Contact lens adaptation is not recommended until the resolution of the symptoms, in the following cases:

- Patients with conjunctival hyperemia or symptoms of conjunctivitis.

- Patients with suspected or confirmed COVID-19.

In patients with a confirmed diagnosis of COVID-19, it is recommended:

- To avoid the use of contact lenses.

- If the patient is completely dependent on contact lenses, they can continue wearing them with extreme hygiene, using for this purpose $3 \%$ hydrogen peroxide solutions ${ }^{11}$.

\section{Urgent surgeries}

Several international institutions, including the American Academy of Ophthalmology ${ }^{10}$, the American Society of Retina Specialists ${ }^{8}$, the American College of Surgeons ${ }^{27}$ and others ${ }^{7}$, have agreed to defer elective surgical procedures to decrease the risk of exposure to SARS-CoV-2 for patients and healthcare personnel.

In the field of ophthalmology, it is recommended to divide the indications for surgical procedures into three groups:

1) Urgent: those that, if surgery is not performed immediately, have a high risk of causing serious and irreversible visual loss.

2) Priority: those that, if surgery is not performed, carry a certain risk of visual loss in the short term, but that may be deferred for a certain time. 
3) Elective: those that, if surgery is not performed, do not carry a risk of visual loss in the short term.

The following is a list of examples of the different procedures included in each group. The list is not intended to be exhaustive. It is worth mentioning that the surgeon is the one who will have the last decision on the surgical indication regarding a particular patient:

\section{Urgent surgeries (highest priority)}

- Acute endophthalmitis requiring vitrectomy.

- Acute macula-on retinal detachment.

- Acute retinal detachment with recent macular involvement ( $\leq 5$ days).

- Retained lens fragments causing inflammation or ocular hypertension that cannot be controlled with medication.

- Open-globe injury with or without an intraocular foreign body.

- Ocular perforation requiring conjunctival flap/scleral patch.

- Dense vitreous hemorrhage in a monocular patient.

- Implant (band, valve) exposed and/or infected.

- Any acute intraocular pressure increase $\geq 40 \mathrm{mmHg}$ that cannot be managed with medication (eg, phacomorphic glaucoma, neovascular glaucoma, acute glaucoma attack).

- Appositional suprachoroidal hemorrhage.

- Retrobulbar hemorrhage.

- Retinopathy of prematurity requiring laser, vitrectomy, scleral buckling, intravitreal antiangiogenics.

- Vitreous biopsy for suspected lymphoma.

\section{Priority surgeries (may be deferred for some time)}

- Acute retinal detachment with macular involvement > 5 days.

- Retained lens fragments with medically controlled inflammation and/or intraocular pressure.

- Vitreous hemorrhage with evidence of retinal tear by ultrasound.

- Glaucoma surgeries with IOP $\leq 40 \mathrm{mmHg}$.

- Eyelid trauma with or without lacrimal duct involvement.

- Special cases of cataract surgery:

- Cataract that prevents photocoagulation in a patient with proliferative diabetic retinopathy.

- Congenital cataract with the risk of amblyopia.

- Blunt ocular trauma with loss of lens capsule integrity.

\section{Elective surgeries (to be suspended until after the contingency)}

- Routine cataract extraction (as long as it can be performed later).

- Pterygium excision.

- Any refractive surgery.

- Any cosmetic surgery.

- Strabismus surgery.

- Penetrating/non-penetrating keratoplasty due to an optical indication.

- Macular hole.

- Epiretinal membrane.

- Vitreomacular traction.

In addition to the ophthalmic indication regarding the urgency of the procedure, we must evaluate each case on an individual basis. We must consider these recommendations to limit potentially contagious contacts; however, the final decision will depend on common sense and clinical evaluation, as well as the epidemiological phase at the moment.

\section{Intravitreal injections and associated tests}

The population that usually requires intravitreal injections is the population with the highest risk of suffering serious consequences from COVID-19 (patients > 60 years of age, with diabetes, hypertension, respiratory problems), so efforts should be directed to prevent these patients from coming to the office, unless the procedure is considered urgent. The relative urgency to perform an intravitreal injection will mainly depend on the diagnosis, as described below:

- Acute endophthalmitis: all patients with suspected acute endophthalmitis should receive an intravitreal injection of an antibiotic in the same way and with the same urgency as in a period without contingency.

- Wet age-related macular degeneration (wet AMD)/choroidal neovascularization: since it has been widely demonstrated that eyes with wet AMD that do not receive injections at regular intervals have a visual loss that is often irreversible ${ }^{33}$, these patients should continue receiving injections according to the required schedule.

- Neovascular open-angle glaucoma: patients with neovessels in the angle and ocular hypertension WITHOUT angle-closure, may benefit from receiving intravitreal injections ${ }^{34}$ with the aim of inducing neovessel regression and either improving intraocular pressure control or reducing the bleeding associated with filtering surgery. It is NOT indicated to defer injections in these cases. 
- Diabetic macular edema/macular edema secondary to venous occlusions: unlike eyes with wet $A M D$, in eyes with diabetic macular edema or retinal vein occlusion, postponement of the injection generally does not jeopardize the visual prognosis, and can be compensated by resuming injections.

\section{References}

1. Khanna RC, Honavar SG. All eyes on Coronavirus-What do we need to know as ophthalmologists. Indian J Ophthalmol. 2020;68:549-53.

2. Wu D, Wu T, Liu Q, Yang Z. The SARS-CoV-2 outbreak: what we know. Int J Infec Dis. 2020;pii: S1201-9712(20)30123-5.

3. Lai T, Tang E, Chau S, Fung K, Li, K. Stepping up infection control measures in ophthalmology during the novel coronavirus outbreak: an experience from Hong Kong. Graefes Arch Clin Exp Ophthalmol. 2020;doi:10.1007/s00417-020-04641-8.

4. van Doremalen N, Bushmaker T, Morris DH, Holbrook MG, Gamble A Williamson BN, Tamin A, et al. Aerosol and surface stability of SARS CoV-2 as compared with SARS-CoV-1. N Engl J Med. 2020; doi:10.1056/ NEJMc2004973.0-2

5. Seah I, Su X, Lingam G. Revisiting the dangers of the coronavirus in the ophthalmology practice. Eye. 2020;doi:10.1038/s41433-020-0790-7.

6. Li JO., Lam DSC, Chen Y, DSW. Novel Coronavirus disease 2019 (CO VID-19): The importance of recognising possible early ocular manifestation and using protective eyewear. Br J Ophthalmol. 2010;104(3):297-8.

7. American Retina Forum. American Retina Forum Coronavirus Response. 2020. Available at: https://www.americanretinaforum.com/coronavirus-response.

8. American Society of Retina Specialists. COVID-19: Member Update American Society of Retina Specialists (ASRS) Member Alert Regarding the COVID-19 Pandemic. 2020. Available at; https://www.asrs.org/practice/ asrs-member-alert-regarding-covid-19-pandemic.

9. American Academy of Ophthalmology. Alert : Important coronavirus up dates for ophthalmologists. 2020. Available at: https://www.aao.org/headline/alert-important-coronavirus-context.

10. American Academy of Ophthalmology. New recommendations for urgent and nonurgent patient care. 2020. Available at: https://www.aao.org/headline/new-recommendations-urgent-nonurgent-patient-care.

11. Sociedad Española de Oftalmología. Recomendaciones para la atención a pacientes oftalmológicos en relación con emergencia COVID-19. 2020. Available at: https://www.oftalmoseo.com/documentacion/comunicado conjunto oftalmologia covid19.pdf.

12. Junk AK, Chen PP, Lin SC, Nouri-Mahdavi K, Radhakrishnan S, Singh K, et al. Disinfection of Tonometers: A Report by the American Academy of Ophthalmology. Ophthalmology, 2017:124:1867-75.

13. Kampf G, Todt D, Pfaender S, Steinmann E. Persistence of coronaviruses on inanimate surfaces and their inactivation with biocidal agents. J Hosp Infect. 2020;104:246-51.

14. United States Environmental Protection Agency. Disinfectants for Use Against SARS-CoV-2. 3-5. 2020.Available at: https://www.epa.gov/pesticide-registration/list-n-disinfectants-use-against-sars-cov-2.

15. Parrish RK 2nd Stewart MW, Duncan Powers SL. Ophthalmologists Are More Than Eye Doctors-In Memoriam Li Wenliang. Am J Ophthalmol. 2020;pii: S0002-9394(20)30067-2.
16. WHO. Coronavirus disease (COVID-19) outbreak. Emergencies - Diseases 2020. 2020. Available at: https://www.who.int/emergencies/diseases/ novel-coronavirus-2019.

17. ENTUK. Loss of sense of smell as marker of COVID-19 infection. 2020 Available at: https://www.entuk.org/loss-sense-smell-marker-covid-19-infection.

18. American Academy of Otolaryngology - Head and Neck Surgery. AAOHNS : Anosmia, hyposmia and dysgeusia symptoms of coronavirus disease. 2020. Available at: https://entnet.org/content/coronavirus-disease-2019-resources.

19. Secretaria de Salud México. Comunicado Técnico Diario Nuevo Coronavirus en el Mundo (COVID-19) 20 marzo 2020. 2020. Available at: hhttps:// www.gob.mx/salud/documentos/coronavirus-covid-19-comunicado-tecnico-diario-238449?idiom=es.

20. Peng, Y. \& Zhou, Y.-H. Is novel coronavirus disease (COVID-19) transmitted through conjunctiva? J Med Virol. 2020. doi:10.1002/jmv.25753.

21. Seah I, Agrawal R. Can the Coronavirus Disease 2019 (COVID-19) Affect the Eyes? A Review of Coronaviruses and Ocular Implications in Humans and Animals. Ocul Immunol Inflamm. 2020; doi: 10.1080/09273948.

22. Chang D, Xu H, Rebaza A, Sharma L, de la Cruz CS. Protecting health-care workers from subclinical coronavirus infection. Lancet Respir Med. 2020;8:e13.

23. Xie X, Li Y, Chwang ATY, Ho PL, Seto WH. How far droplets can move in indoor environments - revisiting the Wells evaporation-falling curve. Indoor Air. 2007;17:211-25.

24. Chen SC, Chio CP, Jou LJ, Liao CM. Viral kinetics and exhaled droplet size affect indoor transmission dynamics of influenza infection. Indoor Air. 2009;19:401-13.

25. Center for Disease Control. How to Protect Yourself Know How it Spreads. 2019. Available at: https://www.cdc.gov/coronavirus/2019-ncov/prepare/ prevention.html.

26. The First Affiliated Hospital. Zhejiang University School of Medicine. Handbook of COVID-19 Prevention and Treatment. 2020.

27. American College of Surgeons. COVID-19: Guidance for Triage of Non-Emergent Surgical Procedures. (2020). Disponbile en: https://www. facs.org/covid-19/clinical-guidance/triage.

28. European league against rheumatism. EULAR Guidance for patients COVID-19 outbreak. 2020. Available at: https://www.eular.org/eular_guidance_for_patients_covid19_outbreak.cfm.

29. D'Antiga L. Coronaviruses and immunosuppressed patients. The facts during the third epidemic. Liver transplantation : official publication of the American Association for the Study of Liver Diseases and the International Liver Transpl. 2020. doi:10.1002/lt.25756.

30. Clinical Trials Arena Roche to start Phase III trial of Actemra in Covid-19 patients. Available at: https://www.clinicaltrialsarena.com/news/roche-actemra-covid-19-trial/.

31. Eye Bank Association of America. Coronavirus Disease 2019 (COVID-19) and Eye Tissue Donation Epidemiological Risk. 2020.

32. Centro Nacional de Transplantes (CENATRA). Recomendaciones al subsistema nacional de donación y trasplantes sobre la infección asociada al SARS-CoV-2 (COVID-19). Available at: https://www.gob.mx/cms/ uploads/attachment/file/541834/Recomendaciones_COVID-19.pdf.

33. Comparison of Age-related Macular Degeneration Treatments Trials (CATT) Research Group. Five-Year Outcomes with Anti-Vascular Endothelial Growth Factor Treatment of Neovascular Age-Related Macular Degeneration: The Comparison of Age-Related Macular Degene. Ophthalmology. 2016;123:1751-61.

34. Wakabayashi T, Oshima $Y$, Sakaguchi H. Intravitreal bevacizumab to treat iris neovascularization and neovascular glaucoma secondary to ischemic retinal diseases in 41 consecutive cases. Ophthalmology. 2008;115:1571-80. 